\title{
Study on infant feeding practices among mothers in rural areas of Faizabad District (U.P.), India
}

\section{Gupta Vandana* \\ Department of Food, Nutrition and Public Health, Ethelind College of Home Science, Sam Higginbottom University of Agriculture, Technology and Sciences, Allahabad-211007 (U.P.), India}

\section{Neeru Bala}

Department of Food, Nutrition and Public Health, Ethelind College of Home Science, Sam Higginbottom University of Agriculture, Technology and Sciences, Allahabad-211007 (U.P.), India

\section{Bose Dipak Kumar}

Department of Agricultural Extension \& Communication, Sam Higginbottom University of Agriculture, Technology and Sciences, Allahabad-211007 (U. P.), India

\section{Kumari Jyoti}

Department of Food, Nutrition and Public Health, Ethelind College of Home Science, Sam Higginbottom University of Agriculture, Technology and Sciences, Allahabad-211007 (U.P.), India

*Corresponding author. E-mail: vandu.v.23@gmail.com

\section{Article Info}

DOI:10.31018/jans.v10i3.1704

Received: April 9, 2018

Revised: June 7, 2018

Accepted: June 25, 2018

\section{How to Cite}

Gupta, V. et al. (2018). Study on infant feeding practices among mothers in rural areas of Faizabad District (U.P.), India. Journal of Applied and Natural Science, 10(3): 831 - 837

\begin{abstract}
The present study was undertaken to find out socio-demographic profile of respondents and to estimate the current feeding practices including breastfeeding, pre-lacteal feeding and complementary feeding. A cross-sectional study was conducted in four blocks namely Haringtonganj, Amaniganj, Bikapur and Sohawal of Faizabad District in 2015. Total 352 lactating mother having children's aged from 6 months to 2 years were interviewed to collect information on pre designed and pretested proforma. The data was tabulated on Microsoft Excel sheet and analysed using chi-square test. Study findings showed that mostly $43.75 \%$ were in the age range of $20-25$ years. More than half $(58.51 \%)$ of the mothers were literate and majority $96.87 \%$ mothers were housewives. All mothers had done breastfeeding in which $73.58 \%$ mothers continued breastfeeding after 6 months at the time of study. Majority $89.49 \%$ responding mothers were given exclusive breastfeeding, $81.82 \%$ had given colostrum and $38.64 \%$ gave pre-lacteal feed to their baby. Most of the children $(80.11 \%)$ were taking weaning food but majority $89.36 \%$ mothers did not prepare any special food for their children. The association between education of mothers and infant feeding practices was found to be statistically significant $(p<0.05)$. The study showed that mostly mothers adopted correct feeding practices at some extent and these practices were much influenced by education of mothers. So it is very necessary to imparting nutrition and health education to the mothers.
\end{abstract}

Keywords: Complementary feeding, Education, Exclusive breastfeeding, Infant, Prelacteal feeding, Socio-demographic profile

\section{INTRODUCTION}

Infant mortality rate (IMR) is considered as one of the most sensitive indicators of health status of a community and malnutrition is one among the commonest causes of infant mortality in a developing country like India. Child is the chief victim of interplay of nutrition and the socioeconomic factors. The under-five population of India stands at a staggering 112.8 million. However, despite all the advances in health, education and agriculture sectors as well as vast improvements in the country's economy, India Figs in the list of countries those have made insufficient progress towards meeting the Millennium Development Goals (Agarwal et al., 2018; Tiwari et al., 2016). According to National Family Health Survey -4 data, the per cent of underweight (weight-for-age) children under 5 years is $45.9 \%$ in rural area of Faizabad district. The children who are stunted (height-forage) and wasted (weight-for-height) found in $51.6 \%$ and $18.9 \%$ respectively.

Under any circumstances breast milk is the ideal food for the infants (Karim et al., 2012). Only Breast Milk offers complete nutrition, early protection against illness and safe healthy food at once. 
The unique characteristic of Breast Milk is that it is baby specific composition (WHO, 2018; Jain et al. 2013). The World Health Organization (WHO) and United Nations Children's Fund (UNICEF) recommends initiation of breastfeeding within the first hour after the birth; exclusive breast feeding for the first six months of life, with the addition of safe, nutritionally adequate, age appropriate, responsive complementary feeds at six months with continued breast feeds until at least the age of two or beyond because the first 2 years of a child's life are particularly important, as optimal nutrition during this period lowers morbidity and mortality, reduces the risk of chronic disease, and fosters better development overall. Over 820000 children's lives could be saved every year among children under 5 years, if all children 0-23 months were optimally breastfed (WHO, 2018).

Breastfeeding practices vary among different regions and communities. The fourth National Family Health Survey (NFHS-4) in rural areas of Faizabad district reported that overall $27.1 \%$ of children aged under three years were breastfed within one hour of birth, $25.5 \%$ of the children aged under 6 months were exclusively breastfed, and only $0.9 \%$ of the children aged 6-23 months received adequate diet with or without breastfeeding. About $36 \%$ of infants aged $0-6$ months worldwide were exclusively breastfed over the period of 20072014. Despite the marked advantages of breast feeding, its popularity has decline significantly in many parts of the world. Formula milk is used in place of breast milk but it is not an acceptable substitute for breast milk because it carries risks of additional illness and death due to danger of the contamination and over dilution of the fat. It is also hard for the baby's gut to absorb anything other than breast milk (UNICEF, 2015; Karim et al. 2012).

According to National Guidelines of Indian Pediatrics, breast milk alone is not enough to make an infant grow well after six months, other foods are also needed which is known as complementary foods. The weaning period is a very vulnerable period. It is the time when malnutrition starts in many infants, contributing significantly to the high prevalence of malnutrition in children under five years of age world-wide. WHO estimates that 2 out of 5 children are stunted in low-income countries. Inappropriate feeding practices are often a greater determinant of inadequate intakes than the availability of foods in the households (WHO, 2018). Knowledge of weaning foods and practices is an important aspect of child health \& development. Efforts should be therefore be made to design and promote the use of feeding practice of infants (Park, 2005; Karim et al. 2012). As there is a paucity of literature on infant feeding practices in this region, the present study was undertaken to estimate the current feeding practices including breastfeeding, pre-lacteal feeding and comple- mentary feeding in selected rural areas of Faizabad district.

\section{MATERIALS AND METHODS}

The present cross-sectional study was conducted at Faizabad District which is situated in Uttar Pradesh, on the bank of River Saryu, about 130 k.m. east of Lucknow. The total population in Faizabad district as per census 2011 stood at 24,70,996 in which $21,30,743$ live in rural and rest $3,40,253$ in urban parts. The per cent of child population in the age group $0-6$ years is $14.6 \%$. According to census 2011, the district contains 11 community development blocks with a rural female literacy rate of $56.5 \%$ which has increased to $62.8 \%$ as per NFHS - 4 data. Among these blocks, four blocks namely Haringtonganj, Amaniganj, Bikapur and Sohawal were purposively selected. Total 352 lactating mothers having children's aged from 6 months to 2 years was interviewed. Random sampling method was used to select the study population. The information about participants demography and infant feeding practices towards breast feeding, pre-lacteal feeding and complementary feeding were collected from the mothers on pre designed and pretested proforma. Face to face interview technique was used to collect data from children's mother. The data was collected, checked, verified and then enter into the computer. Data were analyzed with the help of MS-excel software. The frequency and percentages of various responses were carried out and results are given in percentage. For qualitative data, chisquare test was applied. $P$ value $<0.05$ was taken as statistically significant.

\section{RESULTS AND DISCUSSION}

Socio-demographic profile: A total of 352 mothers having children in the age group 6 months to 2 years were interviewed and the response rate was $100 \%$. Out of 352 mothers, $56.82 \%$ (200) belonged to joint family and $43.18 \%$ (152) belonged to nuclear family. Similar findings were reported by Parashar et al., (2017) in selected Anganwadis of Shimla district of Himachal Pradesh where the rate of joint family was $56 \%$ and nuclear family was $42 \%$. A high per cent of joint family $(83.06 \%)$ than nuclear family (16.94\%) was also obtained by Cacodkar et al., (2016) in rural mothers of Goa. Other studies conducted in Dehradun by Saxena and Kumar (2014) and Udaipur by Jain et al., (2013), the rates were also almost similar with $64 \%$ and $61.05 \%$ respectively. However in studies conducted by Wagh et al., (2013), Karim et al., (2012) and Patil et al., (2009), the rates were lower with $37.8 \%$ in Maharastra, $40.3 \%$ in Dhamrai and $41.5 \%$ in urban slum of Western India respectively. In our study, majority of $53.12 \%$ (187) had 5 -10 member in a family whereas $36.36 \%$ (128) had $0-5$ member and only $10.51 \%$ (37) had $>10$ 
Table 1. Socio demographic profile of the subjects ( $n-352)$.

\begin{tabular}{llll}
\hline Family Types & Characteristics & Frequency & Per cent \\
\cline { 2 - 3 } Family Size & Nuclear & 152 & 43.18 \\
& Joint & 200 & 56.82 \\
Age & $0-5$ & 126 & 35.79 \\
& $5-10$ & 189 & 53.69 \\
& $>10$ & 37 & 10.51 \\
& $20-25$ & 154 & 43.75 \\
Education & $25-30$ & 138 & 39.20 \\
& $30-35$ & 38 & 10.79 \\
& $>35$ & 22 & 6.25 \\
& Illiterate & 146 & 41.48 \\
& Primary & 70 & 19.89 \\
Working status & Middle & 65 & 18.46 \\
Age of child (month) & High school & 37 & 10.51 \\
& Intermediate & 21 & 5.96 \\
& Graduate and Above & 13 & 3.69 \\
Sex of children & Housewife & 341 & 96.87 \\
& Working Lady & 11 & 3.12 \\
& $6-12$ & 157 & 44.60 \\
& $12-18$ & 118 & 33.52 \\
& $18-24$ & 77 & 21.87 \\
& Male & 187 & 53.12 \\
\hline
\end{tabular}

Table 2. Distribution of the respondents by duration of stopped breastfeeding [n=93].

\begin{tabular}{lcccc}
\hline If stopped, & \multicolumn{4}{c}{ Age at which stopped feeding (month) } \\
\cline { 2 - 5 } then & $\mathbf{1 - 6}$ & $\mathbf{6 - 1 2}$ & $\mathbf{1 2 - 1 8}$ & $\mathbf{1 8 - 2 4}$ \\
\hline Frequency & 37 & 20 & 26 & 10 \\
Percentage (\%) & 39.78 & 21.50 & 27.96 & 10.75 \\
\hline
\end{tabular}

Table 3. Distribution of the respondents by frequency of breastfeed in a day [ $n=259]$.

\begin{tabular}{lllllll}
\hline If continued, & \multicolumn{2}{l}{ No. of feeding/day } & & & \\
then & $\mathbf{1 - 3}$ & $\mathbf{3 - 5}$ & $\mathbf{5 - 7}$ & $\mathbf{7 - 9}$ & $\mathbf{9 9}$ & When cry \\
\hline Frequency & 7 & 19 & 19 & 11 & 40 & 163 \\
Percentage (\%) & 2.70 & 7.33 & 7.33 & 4.25 & 15.44 & 62.93 \\
\hline
\end{tabular}

Table 4. Association between education of mothers and exclusive breastfeeding.

\begin{tabular}{|c|c|c|c|c|c|}
\hline \multirow[t]{2}{*}{ Factor } & \multicolumn{5}{|c|}{ Exclusive Breast - feeding } \\
\hline & \multicolumn{2}{|c|}{ Given } & \multicolumn{2}{|c|}{ Not given } & \multirow{2}{*}{$\begin{array}{c}\mathrm{X}^{2} / \mathrm{p} \text {-value } \\
\text { (df - 2) }\end{array}$} \\
\hline Education & Frequency & Per cent & Frequency & Per cent & \\
\hline Illiterate & 124 & 35.23 & 22 & 6.25 & $6.34 / 0.041$ \\
\hline Primary & 63 & 17.90 & 7 & 1.99 & \\
\hline Middle \& above & 128 & 36.36 & 8 & 2.27 & \\
\hline
\end{tabular}

Table 5. Association between education of mothers and pre-lacteal feeding.

\begin{tabular}{|c|c|c|c|c|c|}
\hline \multirow{3}{*}{$\begin{array}{c}\text { Factor } \\
\text { Education }\end{array}$} & \multicolumn{5}{|c|}{ Pre - lacteal feed } \\
\hline & \multicolumn{2}{|c|}{ Given } & \multicolumn{2}{|c|}{ Not given } & \multirow{2}{*}{$\begin{array}{c}\mathrm{x}^{2} / \mathrm{p} \text {-value } \\
\text { (df - 3) }\end{array}$} \\
\hline & Frequency & Per cent & Frequency & Per cent & \\
\hline Illiterate & 60 & 17.04 & 86 & 24.43 & $8.675 / 0.033$ \\
\hline Primary & 23 & 6.53 & 47 & 13.35 & \\
\hline Middle & 33 & 9.37 & 32 & 9.09 & \\
\hline 2High school & 20 & 5.68 & 51 & 14.49 & \\
\hline
\end{tabular}

Table 6. Association between education of mothers and complementary feeding.

\begin{tabular}{|c|c|c|c|c|c|c|c|}
\hline \multirow{3}{*}{$\begin{array}{l}\text { Factor } \\
\text { Education }\end{array}$} & \multicolumn{7}{|c|}{ Age-wise complementary feeding } \\
\hline & \multicolumn{2}{|c|}{$0-6$} & \multicolumn{2}{|c|}{$6-12$} & \multicolumn{2}{|c|}{$>12$} & \multirow{2}{*}{$\begin{array}{c}\mathrm{x}^{2} / \mathrm{p} \text {-value } \\
\text { (df }-3 \text { ) }\end{array}$} \\
\hline & Frequency & Per cent & Frequency & Per cent & Frequency & Per cent & \\
\hline Illiterate & 31 & 10.99 & 54 & 19.15 & 40 & 14.18 & $23.399 /$ \\
\hline Primary & 18 & 6.38 & 36 & 12.76 & 4 & 1.42 & 0.0006 \\
\hline Middle & 4 & 1.42 & 37 & 13.12 & 14 & 4.96 & \\
\hline$>$ High school & 10 & 3.55 & 23 & 8.16 & 11 & 3.90 & \\
\hline
\end{tabular}




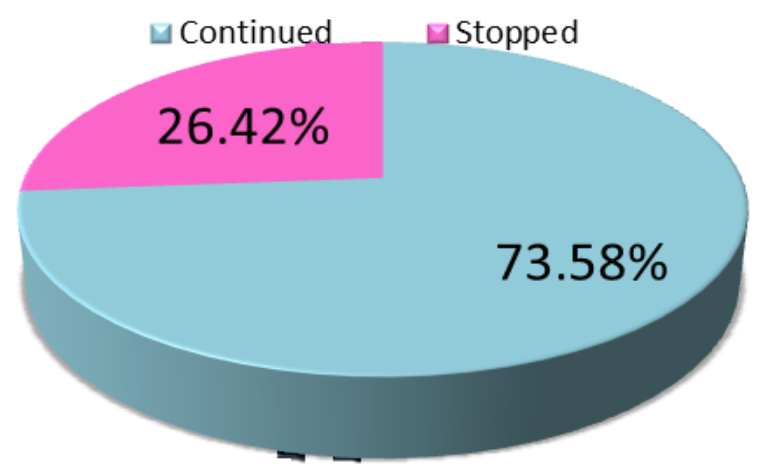

Fig.1. Distribution of the infants by continuation of breastfeeding after six months[ $n=352]$

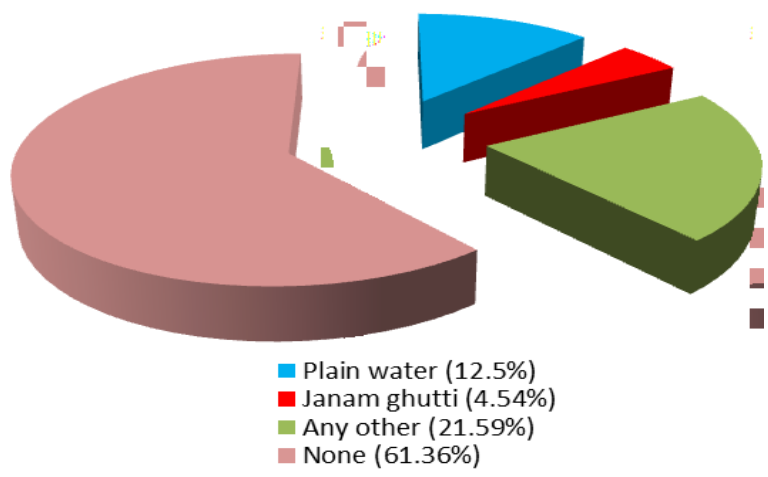

Fig. 3. Distribution of respondents by getting prelacteal feed $(n=352)$.

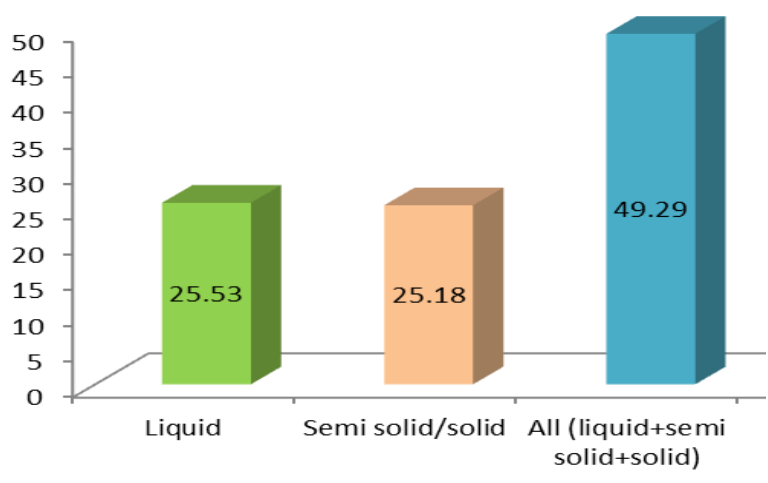

Fig. 5. Distribution of respondent according to types of food used in weaning $(n=282)$.

member. The study conducted by Gupta et al. (2012) in Lucknow did not corroborate with present study where majority of families $(37.2 \%)$ had 0-5 member. In the current study, the age of all 352 lactating mothers ranged between 20-35 years and above in which $43.75 \%$ (154) were in the age range of $20-25$ years, $39.2 \%$ (138), $10.79 \%(38)$ and $6.25 \%(22)$ in the range of $25-$ $30,30-35$ and more than 35 years respectively. These findings were similar with findings conducted by Cacodkar et al., (2016) in rural mothers of Goa where the per cent of mothers having age 20 -25 years was higher $(43.3 \%)$ than others. Farah and Karim (2015) also found high per cent of mothers $(81.5 \%)$ in age range of $20-30$ years in

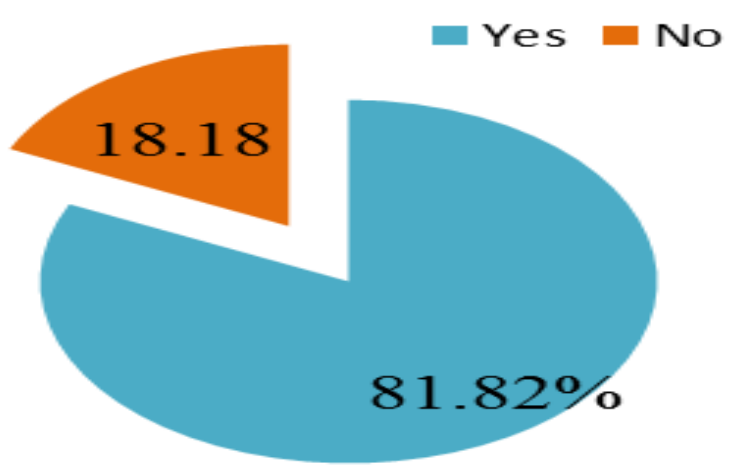

Fig. 2. Distribution of respondents by getting colostrum feed $(n=352)$

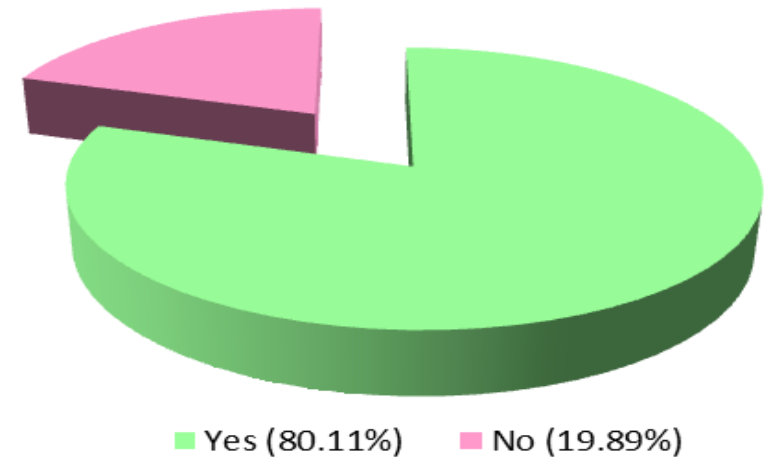

Fig. 4. Distribution of respondents according to take weaning food $(n=352)$

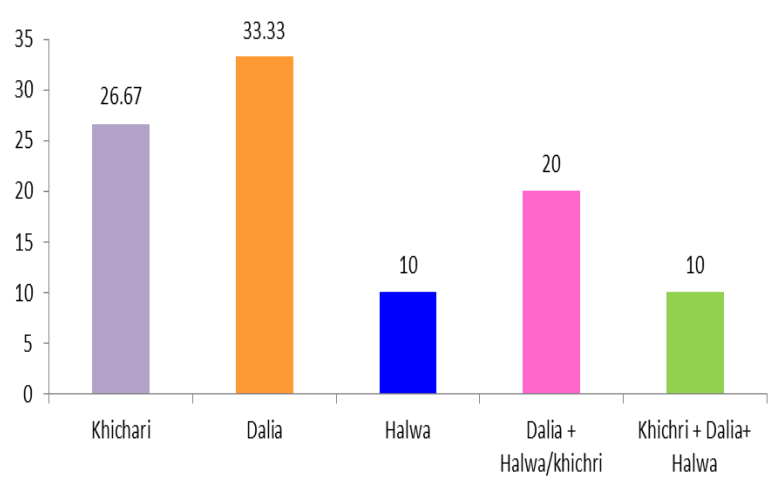

Fig. 6. Distribution of respondent by getting special food $(n=30)$.

Dinajpur District and 70\% mothers having age between 20 to 29 years were observed by Kalita and Borah (2016) in rural areas of Assam. The infant feeding practices are affected by types of family, size of family and age of mothers because if the number of members in family are large, the mother gets more time for adequate feeding and caring of their children and the mother's age is also associated with their educational status which affects feeding practices of children.

More than half $58.51 \%$ (206) of the mothers were literate in which mostly $19.89 \%(70)$ had primary education and $18.46 \%$ (65) had middle level education. On occupation status, majority of mothers $96.87 \%$ (341) were housewives. Only $3.12 \%$ (11) 
were employed. These findings were almost similar with the findings of Kakati et al., (2016) in rural areas of Kamrup district, Assam, where 28.8\% mothers had primary education, $16.8 \%$ had middle level education and $19.2 \%$ had above education. In other studies of Farah and Karim (2015) in Dinajpur District, most of the mothers $(47.2 \%)$ had primary education and $94.1 \%$ mothers were housewife. Kalita and Borah (2016) also found high per cent of housewives (70.2\%) in rural areas of Assam. Out of 352 children studied, $44.6 \%$ (157) belonged to the age of 6-12 months, followed by $33.52 \%$ (118) of $12-18$ months and $21.87 \%(77)$ of $18-24$ months. More than half of the children $53.12 \%$ (187) were male and $46.87 \%$ (165) were female (Table-1). Study findings of Saxena and Kumar (2014) also showed that $48.5 \%$ children were in the age of $0-6$ months followed by $36.3 \%$ of $6-12$ months, $12.5 \%$ of $12-18$ months and $2.7 \%$ of $18-24$ months. The percentage of male children $(52.1 \%)$ was more than female children (47.9\%) in their study. Kakati et al., (2016) observed almost similar results in rural Assam where the per cent of male children was $56 \%$ and female children were $44 \%$.

Practices related to feeding: Among 352 lactating mothers, all mothers had done breastfeeding to their children in which $73.58 \%$ (259) mothers continued breastfeeding after 6 months whereas $26.42 \%$ (93) mothers had stopped breastfeeding at the time of interview (Fig. 1). Among 93 respondents, $27.96 \%$ (26) mothers had stopped breastfed their infants by duration of $12-18$ months and $39.78 \%(37), 21.5 \%$ (20) \& $10.75 \%$ (10) were stopped at 1-6 months, 6-12 months and 18-24 months respectively (Table-2). So the findings of this study showed that about ninety per cent $(89.49 \%)$ responding mothers were given exclusive breastfeeding which was much higher compared to $25.5 \%$ in rural areas of Faizabad district conducted by NFHS-4. The per cent of exclusive breastfeeding has increased from $46.4 \%$ in NFHS-3 to $54.9 \%$ in NFHS-4 at national level. According to NFHS-4 data, only $8.7 \%$ children were received breastfeeding with adequate diet by duration of 6-23 months in India which was also lower than the present study. The most similar observation was found by Agarwal et al., (2018) where the per cent of exclusive breastfeeding was $89.7 \%$ in rural area of Bareilly district, Uttar Pradesh. In other findings, $66 \%$ mothers practiced exclusive breastfeeding in rural areas of Assam conducted by Kakati et al., (2016). Karim et al. (2012) also reported the higher per cent of exclusive breastfeeding $(70 \%)$ and observed that $38.8 \%$ breastfed their infants by the duration of 6 9 months and $42.8 \%$ were $9-12$ months in Dhamrai. In continuation of breastfeeding, mostly $62.93 \%$ (163) breastfed their infants on crying which is known as demand feeding. $15.44 \%$ (40) mothers breastfed their infants more than 9 times in a day whereas $4.25 \%$ (11), $7.33 \%$ (19), $7.33 \%$ (19) and $2.7 \%$ (7) breastfed their baby $7-9,5-7,3-$ 5 and 1-3 times in a day respectively (Table-2). The study of Vyas et al. (2012) in rural areas of Uttarakhand also formulated that high per cent of mothers $(89.1 \%)$ breastfed their infants on demand and $10.9 \%$ at regular intervals in a day.

The use of colostrums and avoidance of pre lacteal food is the cornerstone in early infant's nutrition and may be prerequisite for the establishment of future of breast feeding. Pre-lacteal food was defined as food/liquid given to infant before initiation of breast feeding for the first time. In present study, majority of the women $81.82 \%$ (288) had given colostrum to their baby (Fig. 2). More than half $61.36 \%(216)$ of mothers did not give prelacteal feed to their children. Out of those who had given pre-lacteal feed, $12.5 \%$ had given plain water and $4.54 \%$ had given janam ghutti to their children. Other $21.59 \%$ had given honey, powdered milk, cow's milk and goat's milk (Fig. 3). This study was almost supported by Jha et al. (2016) findings where $83.8 \%$ mothers had given colostrums to their baby and the prevalence of prelacteal feeding was $40 \%$ in rural field practice area of Kakatiya Medical College, Warangal, Telangana. Other researcher reported the prevalence rate of pre-lacteal feeding was $20.5 \%$ in Bareilly district by Agarwal et al., (2018), $14.8 \%$ in rural mothers of Tamilnadu by Shankar \& Muthukumar (2015), $15.85 \%$ in Maharastra by Wagh et al. (2013), $29.3 \%$ in Tamilnadu by Jennifer et al. (2012).

Out of 352 respondents, $80.11 \%$ were taking weaning food at the time of study with or without breastfeeding and $19.89 \%$ were not taking weaning food. On the type of weaning foods given to the infants, $49.29 \%$ of the nursing mothers preferred all types of foods like liquid, semi solid and solid foods whereas $25.53 \%$ provided only liquid foods and $25.18 \%$ offered only semi solid or solid foods (Fig. 5). In present study, 89.36\% mothers did not prepare any special food for their children. Out of 30 mothers, only $33.33 \%$ mothers used dalia as complementary food for their children, $26.67 \%$ used khichri, $20 \%$ used dalia with halwa/ khichri, $10 \%$ used all types \& $10 \%$ used halwa as complementary feed (Fig. 6). Most similar results was obtained by Saxena and Kumar (2014) in Doiwala district, Dehradun where 87.3 per cent of children above 6 month of age were on complementary feeding, however in $12.7 \%$ of cases , complementary feeding was not started at the time of study. In rural areas of Assam, Kakati et al., (2016) found that the complementary feeding was initiated by $54.4 \%$ of mothers at the age of 6 months, $19.2 \%$ of mothers initiated complementary feeding before 6 months of age and $26.4 \%$ of mothers initiated after 6 months of age. Most of the mothers $(56.8 \%)$ had given semi-solid food 
followed by Animal milk (35.2\%). Semisolid includes khishri, suji, gruels and animal milk includes - Cow's milk and goat's milk. In other study of Farah and Karim (2015) in Dinajpur District, $142(50.9 \%)$ respondents were started complementary feeding after six months of age and only $27(9.7 \%)$ started at four months of age. The common types of complementary food were khichuri $(49.7 \%)$, shagu, suji $(21.5 \%)$, fruit juice $(6.8 \%)$ given as family food.

Association between education of mothers and infant feeding practices: The infant feeding practices such as exclusive breastfeeding, prelacteal feeding and complementary feeding were found statistically significant ( $p$-value $<0.05$ ) with educational status of mothers. Above fifty per cent mothers $(54.26 \%)$ who were literate offered exclusive breastfeeding compared to illiterate mothers $(35.23 \%)$. The mothers having middle and above education were reported in higher per cent $(36.36 \%)$ than others (Table-4). Verma and Dixit (2016) conducted study in rural Uttar Pradesh where the association of education status of mother was also seen to be significant with exclusive breast feeding, as it was seen to be a positive correlation. The educational status of lactating mothers also affect the pre-lacteal feeding practices because $36.93 \%$ literate mothers did not provide pre-lacteal feed to their children which was higher than illiterate mothers $(24.43 \%)$. The per cent of mothers having high school education was found high $(14.49 \%)$ than others (Table-5). The present findings was similar with the observation of Jha et al., (2016) where they noticed to be proportional increase in mothers not giving prelacteal feeds with proportional increase in education. There was significant relation between education and practice of not giving pre-lacteal feeds in rural field practice area of Kakatiya Medical College, Warangal, Telangana. Whereas Parashar et al., (2017) found that the literacy level of mother was not related to giving pre-lacteal feeds in selected Anganwadis of Shimla district of Himachal Pradesh.

In present study, the higher per cent of literate mothers provided complementary feeding at appropriate age than illiterate mothers. Among literate mothers, mostly mothers having middle level education $(13.12 \%)$ offered complementary foods at right time. The late introduction of weaning foods was done by illiterate mothers in high frequency $(14.18 \%)$ and the early introduction was practiced by literate and illiterate mothers about to equally i. e. 11.35 per cent and 10.99 per cent respectively (Table-6). The education of mothers is a significant factor in improving the nutritional status of infants. Evidently, it affects the appropriate feeding of children which is observed in present study. Similar findings were observed by Kakati et al., (2016) in rural areas of Kamrup district,
Assam where majority of mothers $(81 \%)$ with middle educational status were more likely to initiated complementary feeding at 6 months as compared to illiterate $(36.3 \%)$ and primary school mothers $(51.3 \%)(P<0.0001)$.

\section{Conclusion}

The present study has revealed areas of similarities and a few distinct differences in infant feeding practices when compared with other studies. Majority of mothers provided all feeding practices in our study which is much higher than national Fig.s. Practices like giving pre-lacteal feeds were found in lower per cent but still the prevalence rate is $38.63 \%$ in study area. It is very necessary to adopt the right practices of weaning food for rural mothers. The study shows that the infant feeding practices are influenced by the education of mothers because as the literacy level increases, the frequency of appropriate practices also increases. So, it is concluded that maternal knowledge and awareness of correct feeding practices is essential for the normal growth, health and wellbeing of the children which can be possible through effectiveness of various health education programmes conducted at national level in India.

\section{REFERENCES}

1. Agarwal, M., Joshi, H. S., Tanwar, R., Singh, A., Katyal, R. and Upadhyay, D. (2018). An evaluation: IYCF practices in rural area of Bareilly district, Uttar Pradesh. Int $\mathrm{J}$ Community Med Public Health., 5 (1):308-312

2. Cacodkar, J., Joglekar, Sh. and Dubhashi, A. (2016). Breast feeding and infant feeding practices among rural mothers in Goa. Int $\mathrm{J}$ Community Med Public Health., 3(1):184-189.

3. Census of India (2011). Retrieved May, 162018 from $\mathrm{http}: / / \mathrm{www}$. censusindia.gov.in/2011census /dchb/ DCHB_A/09/0946_PART_A_DCHB_FAIZABAD.pdf

4. C-14 Population in five year age-group by residence and sex. New Delhi; Office of the Registrar General and Census Commissioner, Ministry of Home Affairs, Government of India (2011). Retrieved July, 222015 from http://www.censusindia.gov.in/2011census/Cseries/C-14.html.

5. Farah, Sh. and Karim, M. (2015). Characteristics of Feeding Practices and Nutritional Status of Infants in Selected Villages at Dhamrai. Bangladesh Med Res Counc Bull., 41: 108-113.

6. Jain, U., Jain, J. B., Garg, D., Sharma, U. R. and Agrawal, N. (2013). Knowledge of Breast-feeding and Breast-feeding Practices amongst mothers delivered at tertiary level obstetrics care hospital at Udaipur. Int $J$ Med Pharm Sci., 04 (01):10 - 16.

7. Jennifer, H. G. and Muthukumar, K. (2012). A Cross Sectional Descriptive Study to Estimate the Prevalence of Early Initiation and Exclusive Breast feeding in Rural Health Training Centre of Medical College Tamilnadu, Southern India. Journal of Clinical Diagnostic and Research, 6(9):1514-1517.

8. Jha, P. K., Kumar, K. J. K. and Niharika, L. (2016). Study of breast feeding practices in rural field practice area of Kakatiya Medical College, Warangal, 
Telangana state, India. Int $\mathrm{J}$ Community Med Public Health., 3(9):2661-2666.

9. Kakati, R., Barua, R. and Borah, M. (2016). Complementary feeding practices and its determinants in rural areas of Kamrup district, Assam, India. Sch. J. App. Med. Sci., 4(6F):2260-2265.

10.Kalita, D. and Borah, M. (2016). Current practices on infant feeding in rural areas of Assam, India: a community based cross sectional study. International Journal of Community Medicine and Public Health, 3 (6): 1454-1460.

11.Karim, Dr. M., Farah, Dr. Sh. and Ferdousi, Dr. J. (2012). Study on feeding practices of infants among the mothers in selected villages at Dhamrai. J. Dhaka National Med. Coll. Hos., 18 (02): 30-36.

12.Ministry of Health and Family Welfare: National Family Health Survey-4 (2015-16). Distrct Fact Sheet, Faizabad, U.P. pp. 1-4. Retrieved May, 162018 from http://rchiips.org/nfhs/FCTS/UP/

UP_Factsheet_177_Faizabad.pdf.

13.Ministry of Health and Family Welfare: National Family Health Survey-4 (2015-16). India Fact Sheet. pp. -6. Retrieved May, 162018 from http://rchiips.org/ nfhs/pdf/NFHS4/India.pdf.

14. National Guidelines on Infant and Young Child Feeding (2004). Ministry of Human Resource Development. pp. 1-26. Retrieved May, 172018 from http:// www.wcd.nic.in/sites/default/files/ nationalguidelines.pdf

15.Parashar, A., Sharma, D., Gupta, A. And Dhadwal, D. S. (2017). Pre-lacteal feeding practices and associated factors in Himachal Pradesh. Int $J$ Health Allied Sci., 6:30-4. Available from http://www.ijhas.in/ text.asp?2017/6/1/30/200205

16.Park, K. (2005). Park's Textbook of Preventive and Social Medicine. 20th ed. Publishers: Banarsidas Bhanot, Jabalpur, India. pp 457.

17.Patil, S. S., Hasamnis, A. A., Pathare, R. S., Parmar, A., Rashid, A. K. and Narayan, K. A. (2009). Exclusive Breast Feeding and its correlates in an urban slum in Western India.

18.Shankar K. and Muthukumar S. (2015). Pre lacteal feeding practice among rural mothers in Tamilnadu. International Journal of Biomedical and Advance Research., 6(06): 484-487.
19.Saxena, Dr. V. and Kumar, Dr. P. (2014). Complementary feeding practices in rural community: A study from block Doiwala district Dehradun. Indian Journal of Basic and Applied Medical Research, 3 (2): 358-363.

20.Tiwari, S., Bharadva, K., Yadav, B., Malik, S., Gangal, P., Banapurmath, C. R., Zaka-Ur-Rab, Z., Deshmukh, U., Kumar, V. and Agrawal, R. K. (2016). Indian Pediatrics: Infant and Young Child Feeding Guidelines, 2016. 53:703-713.

21.Verma, A. and Dixit, P. (2016). Knowledge and Practices of Exclusive Breastfeeding among Women in Rural Uttar Pradesh. J Neonatal Biol., 5 (3): 228.

22.Vyas, Sh., Sharma, P., Kandpal, S. D., Semwal, J., Srivastava, A. and Nautiyal, V. (2012). A community based study on breastfeeding practices in a rura area of Uttarakhand. National Journal of Community Medicine., 3 (2): 283 - 287.

23.Wagh, S. V., Wagh, S. S., Raut, M. M., Dambhare, D. G. and Sharma, D. A. (2013). A Study of Breast Feeding Practices in a Vidarbha Region of Maharashtra, India. Innovative Journal of Medical and Health Science, 238 - 241.

24.World Health Organization (2018) Exclusive breastfeeding. Retrieved May, 162018 from http:/l www.who.int/nutrition/topics/exclusive_breastfeeding/ en/

25.World Health Organization (2018). Infant and Young Child Feeding Fact Sheet. Retrieved May, 162018 from http://www.who.int/en/news-room/fact-sheets/ detail/infant-and-young-child-feeding

26.United Nation Children's Fund (2015). Breastfeeding Retrieved May, 162018 from https://www.unicef.org/ nutrition/index_24824.html

27.United Nations Children's Fund (2013). Improving Child Nutrition. The achievable imperative for global progress. New York. Retrieved July, 112015 from www.unicef.org/ publications/index.html.

28.World Health Organization (2018). Complementary feeding. Retrieved May, 162018 from http:// www.who.int/nutrition/topics/complementary_feeding/ en/

29.World Health Organization (2018). Promoting proper feeding for infants and young children. Retrieved May, 162018 from http://www.who.int/nutrition/topics/ infantfeeding/en/ 